University of Nebraska - Lincoln

DigitalCommons@University of Nebraska - Lincoln

Agronomy \& Horticulture - Faculty Publications

Agronomy and Horticulture Department

2018

\title{
Strawberry cultivars vary in productivity, sugars and phytonutrient content when grown in a greenhouse during the winter
}

\author{
Ellen T. Paparozzi \\ University of Nebraska-Lincoln, etp1@unl.edu \\ George Meyer \\ University of Nebraska-Lincoln, gmeyer1@unl.edu \\ Vicki Schlegel \\ University of Nebraska-Lincoln, vschlegel3@unl.edu \\ Erin Blankenship \\ University of Nebraska-Lincoln, erin.blankenship@unl.edu \\ Stacy A. Adams \\ University of Nebraska-Lincoln, sadams1@unl.edu \\ See next page for additional authors \\ Follow this and additional works at: https://digitalcommons.unl.edu/agronomyfacpub \\ Part of the Agricultural Science Commons, Agriculture Commons, Agronomy and Crop Sciences \\ Commons, Botany Commons, Horticulture Commons, Other Plant Sciences Commons, and the Plant \\ Biology Commons
}

Paparozzi, Ellen T.; Meyer, George; Schlegel, Vicki; Blankenship, Erin; Adams, Stacy A.; Conley, M. Elizabeth; Loseke, Benjamin A.; and Read, Paul, "Strawberry cultivars vary in productivity, sugars and phytonutrient content when grown in a greenhouse during the winter" (2018). Agronomy \& Horticulture -- Faculty Publications. 1142.

https://digitalcommons.unl.edu/agronomyfacpub/1142

This Article is brought to you for free and open access by the Agronomy and Horticulture Department at DigitalCommons@University of Nebraska - Lincoln. It has been accepted for inclusion in Agronomy \& Horticulture -Faculty Publications by an authorized administrator of DigitalCommons@University of Nebraska - Lincoln. 


\section{Authors}

Ellen T. Paparozzi, George Meyer, Vicki Schlegel, Erin Blankenship, Stacy A. Adams, M. Elizabeth Conley, Benjamin A. Loseke, and Paul Read 
Published in Scientia Horticulturae 227 (2018), pp 1-9.

Copyright (c) 2017 Elsevier B.V. Used by permission.

doi 10.1016/j.scienta.2017.07.048

Submitted 5 February 2017; revised 5 July 2017;

accepted 27 July 2017, published 3 January 2018.

\title{
Strawberry cultivars vary in productivity, sugars and phytonutrient content when grown in a greenhouse during the winter
}

\author{
Ellen T. Paparozzi, ${ }^{1}$ George E. Meyer, ${ }^{2}$ Vicki Schlegel, ${ }^{3}$ \\ Erin E. Blankenship, ${ }^{4}$ Stacy A. Adams, ${ }^{5}$ \\ M. Elizabeth Conley, ${ }^{5}$ Ben Loseke, ${ }^{5}$ \\ and Paul E. Read ${ }^{5}$
}

\begin{abstract}
1377 Plant Sciences Department of Agronomy and Horticulture, University of NebraskaLincoln, Lincoln, NE 68583-0724

2 Department of Biological Systems Engineering, University of Nebraska-Lincoln, Lincoln, NE 68583-0726

3 Department of Food Science, University of Nebraska-Lincoln, Lincoln, NE 68583-0919

4 Department of Statistics, University of Nebraska-Lincoln, Lincoln, NE 68583-0963

5 Department of Agronomy and Horticulture, University of Nebraska-Lincoln, Lincoln, NE 68583-0724

Corresponding author — E. T. Paparozzi, email etp1@unl.edu
\end{abstract}

\begin{abstract}
In many areas of the US, fresh locally grown berries are not available during the winter. With this in mind, a research study comprised of three experiments was conducted focused on cultivar selection for berry yield, number, sweetness and phytonutrient content. Using a capillary mat system with under bench heating within a double-layer polyethylene greenhouse, strawberries were grown in the Great Plains Region of the US during the winter. During experiment 1, 12 cultivars were grown; berries were weighed, counted and analyzed
\end{abstract}


for sugars and phytonutrients. "Albion" plants produced a high number/mass of berries, had relatively high sugar content but a lower level of phytonutrients when compared to other cultivars. Sugar and phytonutrients concentrations overlapped across cultivars and thus, one cultivar could not be statistically singled out as best. As all cultivars flowered and fruited, two additional 8-month-long experiments were conducted. It took only 7 weeks from potting of dormant crowns for most cultivars to produce fruit. Certain cultivars fruited more successfully during certain months than others, but this was not associated with response time. For example," "Albion", "Chandler", "Darselect", "Evie-2" and "Seascape" plants consistently produced fruit October to early January while "AC Wendy", "Cavendish", "Honeoye" and "Strawberry Festival" plants mainly produced berries in March/April. Summed over experiment 2, "Albion", " Cavendish", "Chandler", " Evie-2", "Portola" and "Seascape" plants produced the greatest mass of berries. "AC Wendy" and "Darselect" berries contained some of the highest levels of sugars while berries from "Chandler", "Darselect", "Evie-2", "Seascape" and "Strawberry Festival" had some of the highest phytonutrient values. In the third experiment, of the 8 selected cultivars, "Evie-2", "Evie-2+" and "Portola" plants had the highest total yield and average berry mass/plant. "Seascape" and" Chandler" plants were second in total production. Glucose, fructose and sucrose levels varied across cultivars with "Chandler" and "Seascape" berries possessing the lowest level of total sugars. Phytonutrient values varied among cultivars with some having better flavonoids ("Seascape"), phenols ("Seascape" and "Chandler") and ant oxidant capacity ("Seascape", "Evie-2" and "Cavendish"). Measurement of soluble solids concentration varied by week among the cultivars with "Seascape", "Seascape+", and "Albion" berries possessing higher levels than other cultivars such as "Cavendish". Overall, under these winter greenhouse conditions using capillary mat fertigation and an under-bench heat delivery system, strawberries were successfully produced for the off-season market.

Keywords: Fragaria $\times$ ananassa, Bottom heat, Capillary mat, Soluble solids concentration, Glucose, Fructose, Sucrose, Sweetness index, Phenols, Flavonoids, Ant oxidant capacity, Yield

\section{Introduction}

Strawberries are one of Americans' favorite fruits and shoppers are accustomed to always having berries available in the grocery store. In 2011, $81 \%$ of fresh marketed strawberries were grown domestically. However, to meet consumer demands, 394.2 million pounds of fresh and frozen strawberries were also imported from Mexico during the winter season (Boriss et al., 2010). With increasing shipping costs and seasonal price 
peaks near holidays, such as Thanksgiving and Christmas, and the influence of the local food movement, winter-grown strawberries present an opportunity for increasing and diversifying regional food production. In addition to their popularity as a fresh fruit, cream and fragrance products. As a first step towards year-round production, Mattas et al. (1997) examined the economic feasibility of extending the harvest season. They observed that although strawberries grown in perlite and turf soilless culture gave a higher yield than the conventional soil system, the gross profit was not enough to offset the investment. Ballington et al. (2008) reported that in the mid-south US, using plastic mulch and four dayneutral cultivars, "Albion" plants produced the highest yield and superior quality fruits. However, they also concluded that at the current market price, it was not profitable to extend the production season of strawberries. In Utah, Rowley et al. (2011) reported a marginal profit after testing four day-neutral cultivars. "Evie 2" and "Seascape" plants gave the most consistent yields and acceptable fruit size when grown in high tunnels, particularly when compared to an economic loss for crops that were field-planted.

The above studies focused on season extension using high tunnels rather than a winter greenhouse production of strawberries. While research and actual winter production has been limited in the US, it has not been in Europe (Takeda and Hokanson, 2002; ; Pritts and Handley, 1998). Countries such as The Netherlands and Belgium have been growing strawberries in buckets and peat bags in greenhouses for decades (Lieten, 1993; Mattas et al., 1997). Thus, it is feasible that regions of the US with high winter light conditions, such as the Great Plains, could allow for winter berry production.

However, heat costs could still limit profitability. Therefore, we designed a resource conservation-minded growing system that minimizes water, fertilizer and heat usage and maximizes light reflectance to determine whether we could grow and produce strawberries during the winter season (Paparozzi, 2013). In addition to developing an affordable production system, suitable for any smaller specialty crop farmer, we wanted to evaluate the sweetness and health benefits of potential cultivars that could be grown in our system. With the offseason production goal of obtaining the highest price for the berries, the purpose of this research was to select strawberry cultivars that would produce the most mass and number of berries with the highest phytonutrient content without sacrificing sweetness when grown in a greenhouse during the winter. 


\section{Materials and methods}

Three experiments were completed during winter 2009-spring 2010 (experiment 1-screening experiment), fall 2010 through spring 2011 (experiment 2-cultivar trial), and fall 2011 through spring 2012 (experiment 3-focused trial on successful cultivars). All experiments were conducted in a $7.2 \times 29$ m double-polyethylene covered Quonset-style greenhouse on the East Campus of the University of Nebraska-Lincoln (UNL) (lat. $40^{\circ} 50^{\prime} \mathrm{N}$, long. $96^{\circ} 45^{\prime} \mathrm{W}$ ). Plants were grown on two separate $1.8 \times 18.3$ $\mathrm{m}$ benches oriented north-south with a capillary mat system (CapMat ${ }^{\mathrm{TM}}$ II, Phytotronics ${ }^{\circledR}$, Inc., Earth City, MO) used for fertigation (Lambe et al., 2012; Paparozzi and Meyer, 2012). The capillary mat system consisted of a bottom layer of $0.15 \mathrm{~mm}(6-\mathrm{mil})$ thick multipurpose black plastic sheeting (Polar Plastics Inc., Oakdale, MN), followed by fibrous mat, fed by $0.200 \mathrm{~mm}$ (8-mil) thick RO-DRIP ${ }^{\circledR}$ drip tubes with $20 \mathrm{~cm}$ spacing (John Deere, Moline, IL) on the mat, and then covered with white top/ black bottom polyethylene film (Panda Film ${ }^{\mathrm{TM}}$, Flora Hydroponics, Atlanta, GA). The top plastic film served as a reflective mulch and vapor barrier (Meyer et al., 2012). Fifteen-centimeter plastic pots with bottom holes were interfaced with the mat by using a special jig device to cut holes in the top plastic for each pot by using an $\mathrm{X}-\mathrm{ACTO}{ }^{\circledR}$ knife blade (Elmer's Products, Inc., Westerville, $\mathrm{OH}$ ) as a pivot cutter to scribe the hole to the correct diameter (for description of jig device see Meyer et al., 2010; Adams and Paparozzi, 2014). Pots were spaced at $27.9 \mathrm{~cm}$ on center between rows and $40.6 \mathrm{~cm}$ on center between pots occupying a total area of $0.12 \mathrm{~m}^{2}$ per pot. Benches were hand-constructed from 1.82 $\mathrm{m}$ wide bench fabric (Southeastern Wood Products Company, Griffin, GA) on a wooden frame and set on standard-sized concrete blocks to a height of approximately $1 \mathrm{~m}$. The UNL blended potting mix (soil-lite) was comprised of $33 \%$ perlite, $33 \%$ vermiculite, $28 \%$ peat, and $6 \%$ field soil to which dolomitic limestone and Micromax micronutrient blend (Scotts, Marysville, $\mathrm{OH}$ ) were added. Fertigation applications were made using 100 mg nitrogen (N) L-1 Jack's Professional ${ }^{\circledR} 20 \mathrm{~N}-8.8 \mathrm{P}-16.6 \mathrm{~K}$ general purpose fertilizer (J.R. Peters, Inc., Allentown, PA) alternating with calcium nitrate at $100 \mathrm{mg} \mathrm{N} \mathrm{L}^{-1}(15.5 \mathrm{~N}-0 \mathrm{P}-0 \mathrm{~K})\left(\right.$ YaraLiva $^{\mathrm{TM}}$ CALCINIT $^{\mathrm{TM}}$ greenhouse grade, Tampa, FL), or tap water as determined from plant observations. An Orbit ${ }^{\circledR} 91024$ model timer (Orbit Irrigation Products, Inc., Bountiful, UT) periodically initiated fertigation (usually twice per day for $2 \mathrm{~min}$ ). A SuperDos 30 Model 2.5\% Professional injector (Dosmatic U.S.A., Carrollton, TX) with a 100× proportioner was used. Daily watering schedules were adjusted according to crop and environmental 
conditions to minimize night-time humidity levels and to reduce plant disease and pest pressure.

An active greenhouse ventilation system and 2 forced-air gas furnaces (Modine, Racine, WI) with blowers and directed flashing were attached to $0.5 \mathrm{~m}$ diameter polyethylene tubes mounted underneath each bench. These were controlled by a Groton II system (ACME Engineering and Manufacturing, Inc., Muskogee, OK). A day/night temperature differential was kept in the greenhouse at $21 / 17^{\circ} \mathrm{C}$. A small shaded pole blower was used to take in outside air and blow it between the two layers of polyethylene covering. The greenhouse was fully instrumented to monitor inside and outside temperature, humidity, inside photosynthetically active radiation (PAR) amounts, heat energy used, ventilation, and water/fertilizer utilization events (Meyer et al., 2012). Further, a webcam was used to monitor the plants' growth throughout the experiments. There were no other plants or experiments in the house. The computer monitoring system recorded no light contamination at night.

Based on advice from colleagues and growers, cultivars were selected of both day-neutral and June-bearing strawberries (Table 1) to determine those best suited for sustainable crop production. Bumblebees, Bombus impatiens NATUPOL@ (Koppert Biological Systems, Inc., Howell, MI) were introduced into the greenhouse to enhance pollination once the first flowers began to open.

\subsection{Experiment 1: Winter 2009-Spring 2010}

The purpose of this screening experiment was to determine if strawberries would flower and fruit in the greenhouse during the winter. It was conducted in 2 phases. In the first phase plants were grown during the fall 2009 from strawberry crowns as part of a student laboratory exercise. These plants were from four sources and their crowns were harvested at different dates. For the second phase, twenty-four plants of 13 cultivars (Table 1), totaling 312 plants, were then selected in January of 2010 based on similar number of leaves and plant size. All runners, flowers and fruit were removed, and the plants were repotted in soil-lite mix in $15-\mathrm{cm}$ standard pots with bottom holes. The plants were set in place at the beginning of February 2010. The experiment design was a randomized complete block with a total of 6 replications of four plants each (the four pots comprise the experimental unit), with 3 replications running north-south on each of two benches. Berries were deemed ripe based on a color comparison among berries purchased from a local grocery store and those on the bench and standardized by using the RHS 
Table 1. Strawberry cultivars that were grown in each of the three experiments. Response type is indicated by the superscripts. An asterisk indicates a different source for the crowns. The plus (+) indicates a grade of crowns that possesses a larger root system (as per supplier).

Expt. 1

Winter 2009-Spring 2010

AC Wendya

Albionb

Cavendish $^{\mathrm{a}}$

Chandler ${ }^{\mathrm{a}}$

Darselect $^{\mathrm{a}}$

Evie-2 $2^{b}$

Honeoye $^{\mathrm{a}}$

KRS $-10^{a}$

Seascape ${ }^{b}$

Strawberry Festival/July

Strawberry Festival/Augusta

Sweet Charlie

Tribute $^{\mathrm{b}}$
Expt. 2 Fall 2010 -Spring 2011
Expt. 3

Fall 2011 -Spring 2012
a. June-bearing.
b. Day neutral.
c. Indicates different sources.
d. Premium Grade.

$\begin{array}{ll}\text { AC Wendya } & \text { Albion }^{\mathrm{b}} \\ \text { Albion } \mathrm{B}^{\mathrm{c}, \mathrm{b}} & \text { Cavendish }^{\mathrm{a}} \\ \text { Albion } \mathrm{M}^{\mathrm{c}, \mathrm{b}} & \text { Chandler }^{\mathrm{a}} \\ \text { Cavendish }^{\mathrm{a}} & \text { Evie-2 }^{\mathrm{b}} \\ \text { Chandler }^{\mathrm{a}} & \text { Evie-2 }^{\mathrm{d}, \mathrm{b}} \\ \text { Clancy }^{\mathrm{a}} & \text { Portola }^{\mathrm{b}} \\ \text { Darselect }^{\mathrm{a}} & \text { Seascape }^{\mathrm{b}} \\ \text { Evie-2 }^{\mathrm{b}} & \text { Seascape }^{\mathrm{d}, \mathrm{b}} \\ \text { Honeoye }^{\mathrm{a}} & \\ \text { Portola }^{\mathrm{b}} & \\ \text { Seascape } \mathrm{Fc}, \mathrm{b} & \\ \text { Seascape } \mathrm{N}^{\mathrm{c}, \mathrm{b}} & \\ \text { Strawberry Festival } & \end{array}$

Colour Chart (Red Group 46) (Royal Horticultural Society, 1995). Berries were harvested when ripe and data were summed weekly. Data taken at harvest included individual berry color and mass plus the number of berries each plant produced. Also recorded were dates of first flowering and fruiting, number of plants fruiting, total fruit number, and berry mass (yield) per plant.

\subsection{Experiment 2: September 2010 through April 2011}

Dormant strawberry crowns of 11 cultivars (Table 1) were obtained from one commercial source (Nourse Farms, South Deerfield, MA) and were individually potted in $15-\mathrm{cm}$ standard pots with bottom holes and set in place in mid-September 2010. Another source supplied crowns for 2 of the cultivars and each source was treated separately for statistical purposes. A total of 13 cultivars and 312 plants were potted for this experiment. For observational purposes only, on one bench the capillary mat was covered with white (top)/black (bottom) polyethylene film (6 mil) and the other bench was covered with all-white polyethylene film (6 mil). The goal was to see if the white/black film reduced algae growth. The experiment design was a randomized complete block with a total of 


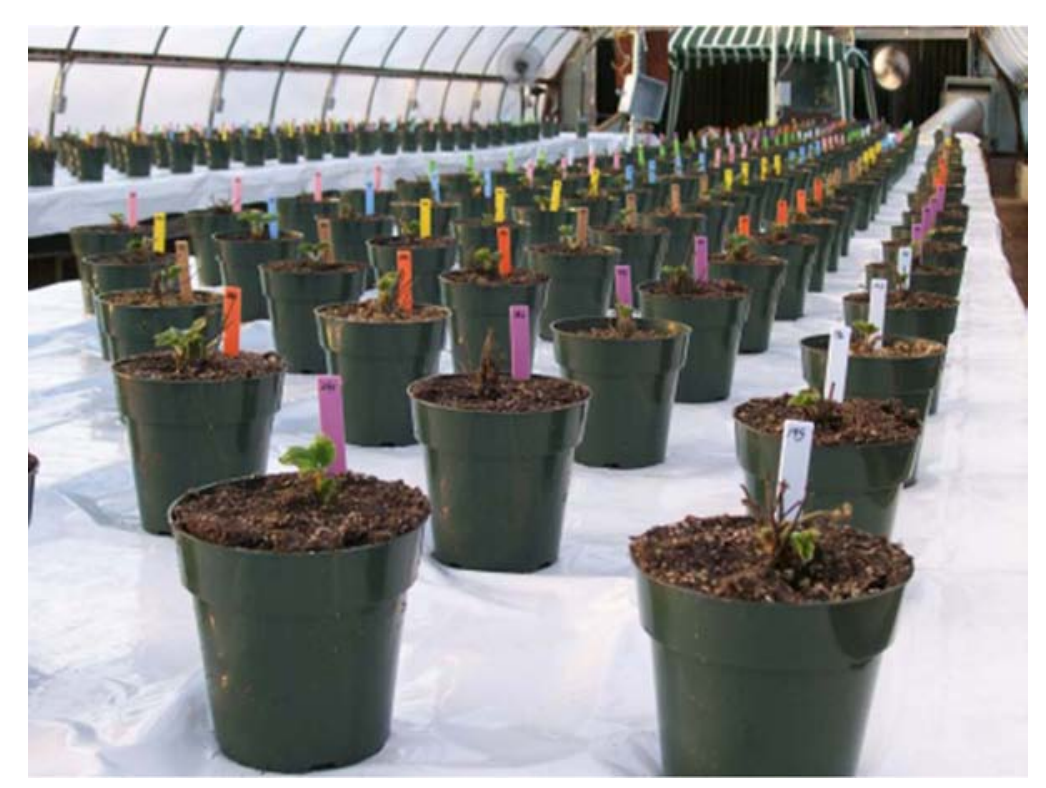

Fig. 1. Experimental layout for 13 strawberry cultivars. Each plant of each cultivar is represented by an unique number and tag color.

6 replications of four plants for each cultivar (the four plants/pots comprise the experimental unit), with 3 replications running north-south on each bench (Fig. 1).

\subsection{Experiment 3: September 2011 through April 2012}

Six strawberry cultivars (Table 1), plus two that were also obtained as + grade larger crowns (more root mass, from the aforementioned commercial source) were potted in individual $15-\mathrm{cm}$ standard plastic pots with bottom holes and set in place in mid-September 2011. The capillary mat of both benches was covered with white (top)/black (bottom) polyethylene film to deter algae growth based on its effectiveness as determined in Experiment 2. The experiment was set up as a randomized complete block design using two benches, with six replications per bench, for a total of twelve replications and up to 48 total plants per cultivar. Four cultivars showed fruit phyllody more than 2 weeks after potting. All plants showing phyllody were discarded, specifically 22 pots of "Portola", 8 pots of "Seascape", 4 pots of "Chandler", and 1 pot of "Albion", reducing the total number of pots in the experiment by 35 ; an additional 50 pots were lost to disease (fungal) and insect problems. Despite this, there was still at least 1 pot of the original 4 pots per experimental unit (replication) remaining. 
For experiment 2 (September 2010 through April 2011) and experiment 3 (September 2011 through April 2012), berry samples were collected from each cultivar during late March for analysis of health-promoting phytochemicals (total phenols, flavonoids, and ant oxidative activity capacity (TEAC)) as well as sugars. They were stored at $-80{ }^{\circ} \mathrm{C}$ prior to analysis at UNL"s Food Science and Technology laboratory facilities. Samples were subsequently extracted with $1.2 \mathrm{~N} \mathrm{HCl}$ in 50:50 water:methanol. After centrifugation, the Folin-Ciocalteu method was used to determine total phenol levels in the sample supernatants as described by Singleton and Rossi (1965). To quantify total flavonoids and ant oxidant capacity, the sample supernatant was prepared and measured according to Adom and Liu (2002) and Cao et al. (1993) respectively. Simple sugar analyses (glucose, fructose, sucrose and total (to include myo-inositol)) were performed to determine sweetness and an index was ascribed to each cultivar for the different samples as described by Keutgen and Pawelzik (2007).

For experiment 3 (September 2011 through April 2012). In addition to the above harvest data, for five consecutive weeks in Spring 2012, 50 $\mathrm{g}$ of ripe berries from 4 replications per cultivar were sampled immediately for soluble solids concentration using an ATAGO Palette PR-101 (045\%) refractometer (ATAGO U.S.A., Inc., Bellevue, WA). Fifty-gram fruit samples were frozen at $-18{ }^{\circ} \mathrm{C}$ for 6 weeks and then analyzed for soluble solids concentration.

\subsection{Data analysis}

All berry mass and number data were analyzed using a repeated measures analysis implemented using the GLIMMIX procedure of SAS (Gbur et al., 2012; Littell et al., 2006). For experiment 2 and 3, data were also analyzed as total numbers and berry mass as well as on a per plant basis. Given that the week each cultivar produced fruit was different and was sometimes zero, the data were transformed to the log scale. The GLIMMIX procedure was then programmed to assume a log normal distribution by using an identity link function. The resulting LSMeans were evaluated using pairwise t-comparisons (alpha $=0.05$ ).

For phytonutrient data, berries were selected from 3 (2010, 20102011) or 4 (2011-2012) replications per cultivar. For 2010-2011 and 20112012, strawberries were also purchased from the grocery store, matched for color using the RHS color chart, analyzed and added to the data as an unknown cultivar to provide a commercial comparison. Instances where there was more than one source of the same cultivar or different 
grades (regular and + , as in experiment 3 ) and where that cultivar responded similarly, the data were pooled. This was determined by running an initial analysis and if the $p$-value $<0.10$ then cultivars were treated separately. Sugar measurements (glucose, fructose, sucrose, total sugars which would include myo-inositol, and sweetness index) were compared among the cultivars using analysis of variance implemented in SAS PROC GLIMMIX. Pairwise comparisons of cultivars were deemed significant at alpha $=0.05$ level. In the third experiment for week 1 and 5 there were not enough berries to analyze for both phytonutrients and soluble solids concentrations of fresh and frozen samples, so emphasis was placed on the phytonutrients.

\section{Results}

\section{1. Experiment 1: Winter 2009 - Spring 2010}

"Albion", "Strawberry Festival" - July and August and "Sweet Charlie" were the first to bear harvestable fruit (3/3/10 week 1 Table 2; data not shown) and all 24 plants of each cultivar flowered and fruited before the end of the experiment. The first harvest was approximately 7 weeks after repotting. Berry color as gauged on the RHS color chart was generally at $46,45,44$ (dark red group) and/or 34 (dark orange-red group) and were comparable in color to those purchased in the grocery store. Often one berry would have two colors depending on which side was viewed. Upon harvest, all cultivars, at some point, produced berries that still had white flesh around the calyx. "Albion" plants produced berries every week and thus the highest total number and mass, followed by "Evie-2", "Seascape", "AC Wendy", "Strawberry Festival" July and "Cavendish" plants (Table 2). Statistical analysis to compare cultivars did not show any significant difference, probably due to the short harvest time and many weeks where no berries were produced. Some cultivars such as "Sweet Charlie" and "Albion" had high two-spotted spider mite (Tetranychus urticae Koch.) infestation, but still flowered and fruited. Thus, the screening experiment indicated that there were strawberry cultivars that would flower under our winter-spring greenhouse conditions.

\subsection{Phytonutrient and sugar studies spring 2010}

In this screening experiment there was no single cultivar that consistently had the highest sugar concentration. For example, "Albion" berries 


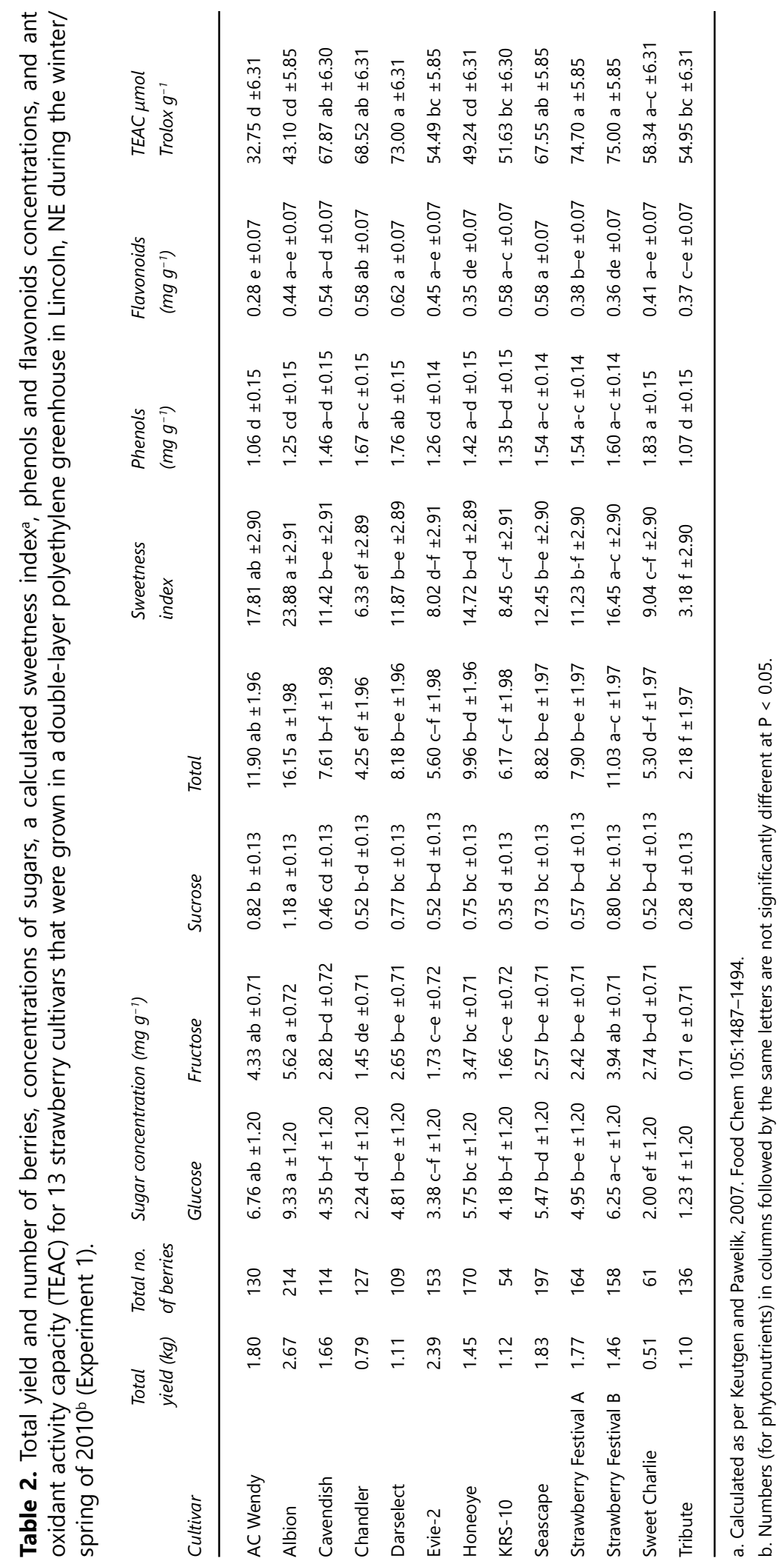


had the highest relative sugar values but were statistically similar, except for sucrose, to "AC Wendy" and "Strawberry Festival B" berries. (Table 2). Sugar concentrations in "AC Wendy" and "Strawberry Festival B" berries in turn were statistically similar to berries of "Cavendish", "Darselect", "Honeoye", "Seascape", "Strawberry Festival A" and "KRS-10". "Cavendish" berries also overlapped with berries that had lower relative, but not statistically significant, levels of sugars in cultivars such as "Evie-2", "Tribute" "Sweet Charlie" and "Chandler".

In terms of phytonutrients, again there was wide overlap across cultivars and thus, statistically, no single cultivar consistently produced berries containing the highest concentration. A few cultivars particularly "Darselect" and "Sweet Charlie" had berries that had high relative concentrations of phenols and flavonoids as well as ant oxidant capacity (Table 2). Of note is that one of the berries with the highest sugar content, "AC Wendy", had statistically lower levels of phenols, flavonoids as well as ant oxidant capacity compared to berries from a cultivar with relatively less sugars, "Seascape" $(P<0.05)$.

As all cultivars regardless of response type did flower and fruit during this winter/spring season, and a baseline of sugar and phytonutrient concentration was established, a full season (8-month) cultivar trial was justified and then conducted the next year.

\subsection{Experiment 2: September 2010 through April 2011}

Five weeks after potting of dormant crowns, "AC Wendy" and "Honeoye" plants were producing berries (data not shown). By the 7th week after potting (Week 4) all cultivars except "Strawberry Festival" were producing strawberries (data not shown). When data were analyzed, the block term was not significant; this indicates that all environmental factors in the greenhouse were similar no matter where the plants were growing and did not influence fruiting. After graphing the raw data and assuring that the distribution was appropriate, data were statistically analyzed for berry mass per plant (Table 3) and total berry mass (data not shown). Starting at week 3 , all interactions particularly week number $\times$ cultivar were significant. During weeks 5-7 (November 27-Dec. 11), total production generally peaked and then dropped at week 8 (some data not shown). At week 6, "Portola" and "Chandler plants" produced significantly more berry mass per plant than "Clancy", "Cavendish", "AC Wendy" and "Seascape $N$ " with the other cultivars falling somewhere in between. At week 7, "Portola" and "Evie-2" plants produced significantly more berry mass per pot than "Albion B", "Clancy", "Honeoye", "Seascape F", "Seascape N" 


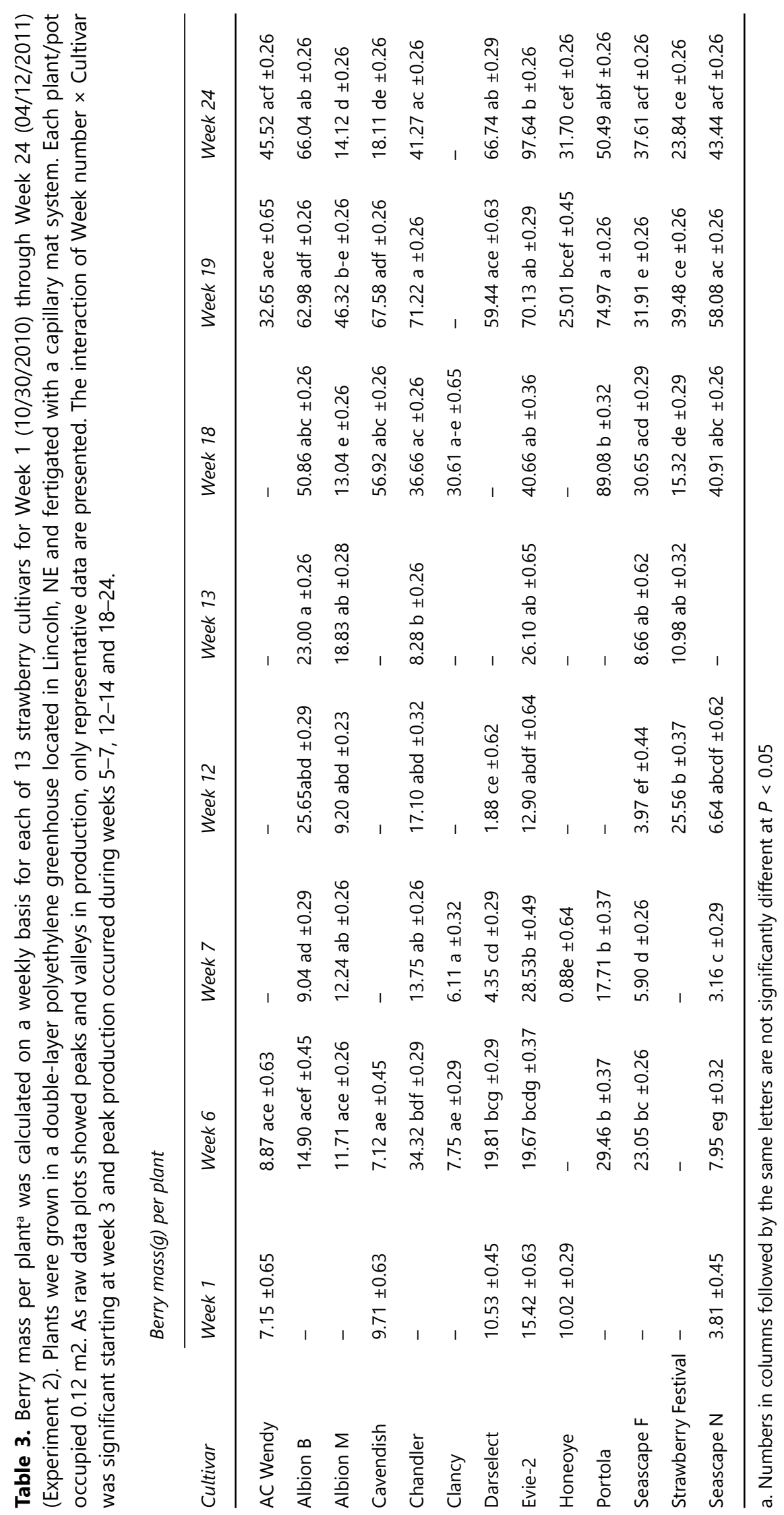


and "Darselect" plants; again with the other cultivars falling in between. During the first 7 weeks, "Strawberry Festival" was the only cultivar that did not produce any fruit.

For weeks 8-16, flowering slowed, often producing little or no fruit, thus, the significant differences were among cultivars or between weeks (data not shown). This was because approximately half of the cultivars were not producing berries. Thus the week by cultivar interaction was less detectable. However, during this time, "Strawberry Festival" plants were starting to produce fruit (week 10) and by week 12 only "Seascape $\mathrm{F}$ " and "Darselect" plants were producing less fruit than most of the other cultivars (Table 3). By week 13, only 6 of the cultivars were flowering and their berry masses were generally similar. At week 18, plants of "Albion $\mathrm{M}$ " and "Strawberry Festival" produced significantly less fruit when compared to the other cultivars. By week 19, all cultivars except for "Clancy" were producing berries and "Chandler" and Portola" plants produced significantly more berries than "Albion M", "Honeoye", "Seascape F", and "Strawberry Festival", but similar to "AC Wendy", "Albion B", "Cavendish", "Darselect", "Evie-2" and "Seascape N" plants. At week 24, "Evie-2" plants produced more berry mass per plant than "AC Wendy", "Albion M", "Cavendish", "Chandler", "Honeoye", "Seascape F", "Strawberry Festival", and "Seascape N", but similar to "Albion B", "Darselect" and "Portola" plants. Starting from week 6 forward, "Albion B", "Albion M", "Chandler", "Evie2 " and "Seascape F" were the cultivars that produced berries consistently over time (complete data not shown).

Over the entire 24 weeks, plants of "Portola", "Seascape F", "Seascape N", "Chandler", "Albion M" and "Darselect" had berry production peaks in both the winter and the spring and thus, produced the most mass (Table 4). "Clancy" plants" berry production peaked only in November. Plants that showed peak berry production in March or March/April only were "AC Wendy", "Albion B", "Cavendish", "Evie-2", "Honeoye" and "Strawberry Festival". Plants that produced less than $4.0 \mathrm{~kg}$ total, $0.2 \mathrm{~kg}$ per plant and had the fewest berries per plant over the 24 weeks were "AC Wendy", "Clancy", "Darselect", "Honeoye" and "Strawberry Festival".

\subsection{Phytonutrient studies September 2010 through April 2011}

In 2010-2011, "Darselect "and "AC Wendy" berries contained significantly higher concentrations of glucose, fructose, total sugars and sweetness index when compared to berries from the grocery store, "Chandler", "Clancy", "Evie-2", "Portola", "Seascape" and "Strawberry Festival B" plants (Table 5). "Darselect" and "AC Wendy" berries also contained 
Table 4. First harvest date and peak harvest times for 13 strawberry cultivars grown from mid-September 2010 through mid-April 2011 (Experiment 2) in double-layer polyethylene greenhouse in Lincoln, NE. Total yield and number of plants, average berry mass and number were not related to response type. ${ }^{a}$ Each plant/pot occupied $0.12 \mathrm{~m}^{2}$.

\begin{tabular}{|c|c|c|c|c|c|c|c|}
\hline Cultivar & Type ${ }^{a}$ & $\begin{array}{l}\text { First } \\
\text { harvest }\end{array}$ & $\begin{array}{l}\text { Peak } \\
\text { harvest }\end{array}$ & $\begin{array}{l}\text { Total } \\
\text { yield }(\mathrm{kg})\end{array}$ & $\begin{array}{l}\text { Ave. berry } \\
\text { mass/plant (kg) }\end{array}$ & $\begin{array}{l}\text { Total } \\
\text { plant number }\end{array}$ & $\begin{array}{l}\text { Ave. berry } \\
\text { number/plant }\end{array}$ \\
\hline AC Wendy & $\mathrm{Jb}$ & 22 Oct. & March & 2.85 & 0.16 & 211 & 12 \\
\hline Albion B & $d-n$ & 16 Nov. & March/April & 10.35 & 0.43 & 1155 & 48 \\
\hline Albion $\mathrm{M}^{\mathrm{b}}$ & $d-n$ & 3 Nov. & December/March & 5.14 & 0.21 & 515 & 21 \\
\hline Cavendish & $\mathrm{Jb}$ & 30 Oct. & March & 8.07 & 0.34 & 664 & 28 \\
\hline Chandler & $\mathrm{Jb}$ & 4 Nov. & December/March & 11.08 & 0.46 & 1271 & 53 \\
\hline Clancy & $\mathrm{Jb}$ & 1 Nov. & November & 0.58 & 0.31 & 96 & 5 \\
\hline Darselect & $\mathrm{Jb}$ & 28 Oct. & $\begin{array}{l}\text { November } \\
\text { April }\end{array}$ & 2.32 & 0.12 & 260 & 13 \\
\hline Evie-2 & $d-n$ & 30 Oct. & March/April & 7.36 & 0.33 & 668 & 30 \\
\hline Honeoye & $\mathrm{Jb}$ & 23 Oct. & March/April & 2.78 & 0.13 & 347 & 17 \\
\hline Portola & $d-n$ & 5 Nov. & $\begin{array}{l}\text { December } \\
\text { March/April }\end{array}$ & 3.10 & 0.32 & 397 & 21 \\
\hline Seascape $\mathrm{F}^{\mathrm{b}}$ & $d-n$ & 2 Nov. & $\begin{array}{l}\text { December } \\
\text { March/April }\end{array}$ & 5.66 & 0.24 & 708 & 30 \\
\hline Seascape $\mathrm{N}^{b}$ & $d-n$ & 29 Oct. & $\begin{array}{l}\text { December } \\
\text { March/April }\end{array}$ & 7.75 & 0.32 & 893 & 37 \\
\hline Strawberry Festival & $\mathrm{Jb}$ & 29 Dec. & March/April & 3.93 & 0.20 & 375 & 19 \\
\hline
\end{tabular}

a. Jb = June-bearing; $d-n=$ day-neutral.

b. Different sources of dormant crowns.

significantly higher concentrations of sucrose when compared to berries from all other cultivars and the grocery store.

Berries from "Darselect", "Seascape" and "Clancy" plants had significantly higher levels of phenols when compared to berries from the grocery store and "AC Wendy", "Cavendish", "Honeoye" and "Portola" plants. "Seascape" berries had a higher concentration of flavonoids than berries from the grocery store and "AC Wendy", "Cavendish", "Chandler", "Honeoye", "Portola", and "Strawberry Festival B" plants. In terms of ant oxidant activity capacity, berries from "Chandler", "Darselect", "Evie-2", and "Seascape" and "Strawberry Festival B" plants contained significantly higher levels than berries from the grocery store and "AC Wendy" and "Portola" plants.

Based on the above yield results (Tables 3 \& 4), "AC Wendy", "Clancy", "Darselect", "Strawberry Festival" and "Honeoye" cultivars were eliminated from the third experiment and only one commercial source was used for all plants. However, other June-bearing cultivars, specifically "Cavendish" and "Chandler" plants produced a substantial amount of berries and thus, were included in the third experiment. 
Table 5. Concentrations of sugars, a calculated sweetness index ${ }^{b}$, phenols and flavonoids concentrations and ant oxidative activity capacity (TEAC) for 13 strawberry cultivars that were grown in a double-layer polyethylene greenhouse in Lincoln, NE during the spring of $2011^{c}$ (Experiment 2).

\begin{tabular}{|c|c|c|c|c|c|c|c|c|}
\hline \multirow[b]{2}{*}{ Cultivar } & \multicolumn{4}{|c|}{ Sugar concentration (mg g-1) } & \multirow{2}{*}{$\begin{array}{l}\text { Sweetness } \\
\text { index }\end{array}$} & \multirow{2}{*}{$\begin{array}{l}\text { Phenols } \\
\left(m g g^{-1}\right)\end{array}$} & \multirow{2}{*}{$\begin{array}{l}\text { Flavonoids } \\
\left(m g g^{-1}\right)\end{array}$} & \multirow{2}{*}{$\begin{array}{l}\text { TEAC } \mu \mathrm{mol} \\
\text { Trolox } \mathrm{g}^{-1}\end{array}$} \\
\hline & Glucose & Fructose & Sucrose & Total & & & & \\
\hline AC Wendy & 3.73 a \pm 0.64 & $2.39 \mathrm{ab} \pm 0.36$ & $2.54 \mathrm{a} \pm 0.32$ & $8.66 a \pm 1.30$ & $12.66 \mathrm{ab} \pm 1.86$ & $0.93 d \pm 0.12$ & $0.31 \mathrm{f} \pm 0.06$ & $46.43 \mathrm{c} \pm 8.28$ \\
\hline Albion & $3.15 a b \pm 0.49$ & $1.75 a-c \pm 0.27$ & $1.38 \mathrm{bc} \pm 0.24$ & $6.28 a b \pm 0.98$ & $9.03 a-c \pm 1.41$ & $1.36 \mathrm{a}-\mathrm{c} \pm 0.12$ & $0.53 a-c \pm 0.06$ & $72.47 \mathrm{ab} \pm 5.86$ \\
\hline Cavendish & $3.36 \mathrm{ab} \pm 0.64$ & $2.20 \mathrm{ab} \pm 0.36$ & $1.05 b c \pm 0.32$ & $6.61 \mathrm{ab} \pm 1.30$ & $9.83 a-c \pm 1.86$ & $1.07 \mathrm{~cd} \pm 0.12$ & $0.42 c-f \pm 0.06$ & $77.40 \mathrm{ab} \pm 8.28$ \\
\hline Chandler & $1.81 b c \pm 0.64$ & $1.21 \mathrm{~cd} \pm 0.36$ & $0.75 b c \pm 0.32$ & $3.77 b c \pm 1.30$ & $5.61 \mathrm{~cd} \pm 1.86$ & $1.34 \mathrm{a}-\mathrm{c} \pm 0.12$ & $0.45 b-f \pm 0.06$ & 89.33 a \pm 8.28 \\
\hline Clancy & $1.88 b c \pm 0.64$ & $1.22 \mathrm{~cd} \pm 0.36$ & $0.65 c \pm 0.32$ & $3.75 b c \pm 1.30$ & $5.56 \mathrm{~cd} \pm 1.86$ & $1.57 \mathrm{a} \pm 0.12$ & $0.52 a-d \pm 0.06$ & $68.53 \mathrm{a}-\mathrm{c} \pm 8.28$ \\
\hline Darselect & 3.74 a \pm 0.64 & $2.57 \mathrm{a} \pm 0.36$ & $2.45 a \pm 0.32$ & $8.75 a \pm 1.30$ & $12.94 \mathrm{a} \pm 1.86$ & $1.55 a \pm 0.12$ & $0.59 a b \pm 0.06$ & $84.76 \mathrm{a} \pm 8.28$ \\
\hline Evie-2 & 1.62 c \pm 0.64 & $1.10 \mathrm{~cd} \pm 0.36$ & $1.19 b c \pm 0.32$ & $3.91 b c \pm 1.30$ & $5.76 \mathrm{~cd} \pm 1.86$ & $1.37 \mathrm{a}-\mathrm{c} \pm 0.12$ & $0.54 a-c \pm 0.06$ & 87.54 a \pm 8.28 \\
\hline Grocery Store ${ }^{a}$ & $1.62 c \pm 0.64$ & $1.04 \mathrm{~cd} \pm 0.36$ & $1.17 b c \pm 0.32$ & $3.83 b c \pm 1.30$ & $5.6 \mathrm{~cd} \pm 1.86$ & $1.07 \mathrm{~cd} \pm 0.12$ & $0.35 d-f \pm 0.06$ & $56.46 \mathrm{bc} \pm 8.28$ \\
\hline Honeoye & $2.42 a-c \pm 0.64$ & $1.48 b-d \pm 0.36$ & $1.52 b \pm 0.32$ & $5.42 a-c \pm 1.30$ & $7.88 b-d \pm 1.86$ & $1.17 b-d \pm 0.12$ & $0.49 \mathrm{~b}-\mathrm{e} \pm 0.06$ & $74.07 \mathrm{ab} \pm 8.28$ \\
\hline Portola & $1.51 c \pm 0.64$ & $0.72 d \pm 0.36$ & $0.73 b c \pm 0.32$ & $2.96 c \pm 1.30$ & $4.16 d \pm 1.86$ & $1.07 \mathrm{~cd} \pm 0.12$ & 0.32 ef \pm 0.06 & $46.58 c \pm 8.28$ \\
\hline Seascape & $1.59 c \pm 0.49$ & $0.87 \mathrm{~d} \pm 0.27$ & $0.94 b c \pm 0.24$ & $3.39 b c \pm 0.98$ & $4.84 \mathrm{~d} \pm 1.41$ & $1.51 \mathrm{a} \pm 0.08$ & $0.64 \mathrm{a} \pm 0.04$ & $81.70 a \pm 5.86$ \\
\hline Strawberry Festival B & $1.51 c \pm 0.64$ & $0.87 d \pm 0.36$ & $0.83 b c \pm 0.32$ & $3.20 b c \pm 1.30$ & $4.62 d \pm 1.86$ & $1.47 \mathrm{ab} \pm 0.12$ & $0.48 b-f \pm 0.06$ & 90.32 a \pm 8.28 \\
\hline
\end{tabular}

a. Purchased at local grocery store; cultivar unknown.

b. Calculated as per Keutgen and Pawelik. 2007. Food Chem 105:1487-1494.

c. Numbers in columns followed by the same letters are not significantly different at $P<0.05$.

\subsection{Experiment 3: September 2011 through April 2012}

All cultivars had at least one plant that started to flower approximately 2.5 weeks after planting (data not shown) and by the end of October, all "Seascape" plants had flowered. By January all plants for each cultivar had flowered. It took between 3 and 4 weeks for flowers of each cultivar to become harvestable fruit (Table 6).

\subsection{Phytonutrient studies September 2011 through April 2012}

In 2011-2012, grocery store berries had statistically higher glucose when compared to berries from "Cavendish" and "Portola" plants. However, grocery store berries did not contain significantly more glucose than berries from "Albion", "Chandler", "Evie-2' and "Seascape" plants (Table 6). Grocery store berries also did not contain significantly more fructose than berries from "Albion", "Cavendish", "Chandler", and "Seascape" plants, but did contain significantly higher fructose concentrations when compared to berries from "Evie-2' and "Portola" plants. Grocery store berries did not contain significantly more sucrose when compared to berries from "Albion, "Chandler", "Evie-2" and "Seascape" plants, but did have statistically higher sucrose concentrations when compared to berries 


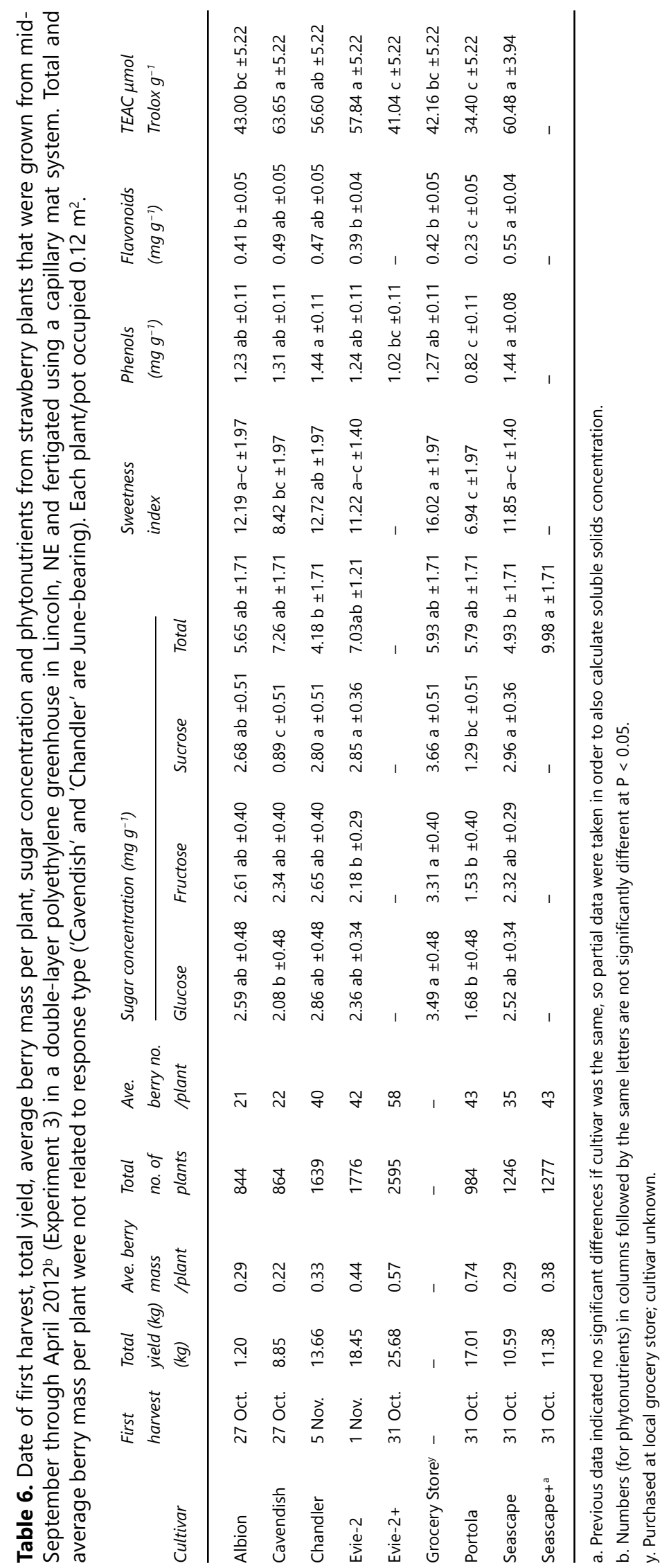


from "Cavendish" and "Portola" plants. "Seascape+" berries had statistically higher total sugars when compared to berries from "Seascape" and "Chandler" plants. "Seascape+" berries did not contain higher total sugars when compared to berries from the grocery store and "Albion", "Cavendish", "Evie-2", and "Portola" plants. Grocery store berries also did not have a significantly higher sweetness index when compared to berries from "Albion", "Chandler", "Evie-2" and "Seascape" plants.

"Seascape" and Chandler" berries contained statistically more phenols than berries from "Portola" plants. "Seascape" and Chandler" berries did not contain more phenols when compared to berries from the grocery store and "Albion" and "Cavendish" plants. In terms of flavonoids, "Seascape" berries had statistically more flavonoids than berries from the grocery store and "Albion", "Evie-2", and "Portola" plants. "Seascape" berries did not contain statistically more flavonoids than "Cavendish" and "Chandler". Seascape", "Cavendish", and "Evie-2" berries had higher ant oxidant capacity than berries from the grocery store and "Albion", "Evie$2+$ " and "Portola" plants.

As in experiment 2, significant block variation for total berry mass per cultivar and berry mass per plant was not observed during the entire experiment. For total berry mass per plant, on week 1, "Evie-2+", "Albion" and "Portola" plants produced more berry mass than "Seascape", "Seascape+" and "Chandler", but similar to "Cavendish" and "Evie-2" (Fig. 2). At week 4, 5 and 6, "Evie-2+" plants produced statistically more berry mass per plant than all of the other cultivars (some data not shown). Weeks 7-9 generally showed low yields for all cultivars and during weeks 10-12 "Portola" and "Cavendish" plants stopped producing berries. "Portola" plants started producing berries again by week 13, when all cultivars were producing a similar berry mass per plant. At week 18 and 19, "Portola" plants produced more berry mass per plant than all other cultivars. At week 24, "Cavendish" plants significantly less berry mass/plant that all other cultivars. "Portola" plants again produced the most berry mass but was similar to berry mass produced by "Evie-2+" and "Evie-2" plants.

Over the entire 24 weeks, "Evie-2+", "Evie-2" and "Portola" plants had the highest average berry mass per plant and the highest total yield (Table 6). "Portola" plants also produced the heaviest berries. "Seascape +"and "Chandler" plants were next averaging between 330 and $380 \mathrm{~g}$ per plant and between 11.38 and $13.66 \mathrm{~kg}$ total production. 


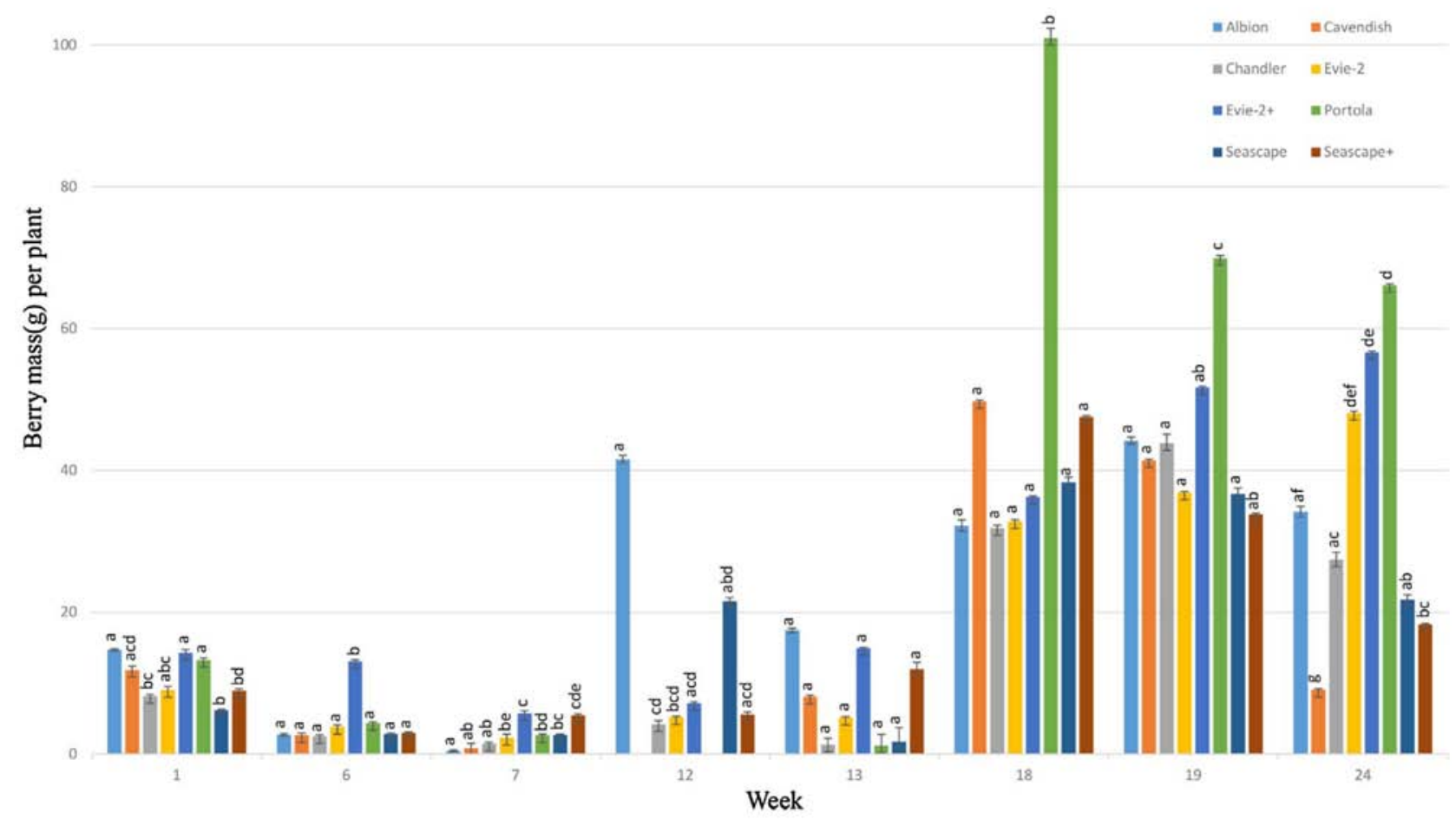

Fig. 2. Berry mass per plant* (LSMeans) was calculated on a weekly basis for each of 8 strawberry cultivars for Week $1(10 / 30 / 11)$ through Week 24 (4/12/2012) (Experiment 3). Plants were grown in a double-layer polyethylene greenhouse located in Lincoln, NE and fertigated using a capillary mat system. Each plant/pot occupied $0.12 \mathrm{~m}^{2}$. As raw data plots showed peaks and valleys in production, only representative data are presented. The interaction of Week number $\times$ Cultivar was significant for all weeks and peak production occurred during weeks 5-7, 12-14 and 18-24. *Numbers in columns followed by the same letters are not significantly different at $P<0.05$.

\subsection{Soluble solids concentration measurements}

There was a difference in soluble solids concentration among cultivars by week for both fresh and the frozen berries such that berries from "Seascape", "Seascape+" and "Albion", which measured above 8, were higher in soluble solids concentration than "Cavendish" berries (Table 7). There was no statistical difference between fresh versus frozen berries both within each cultivar and when averaged over cultivar (data not shown). 


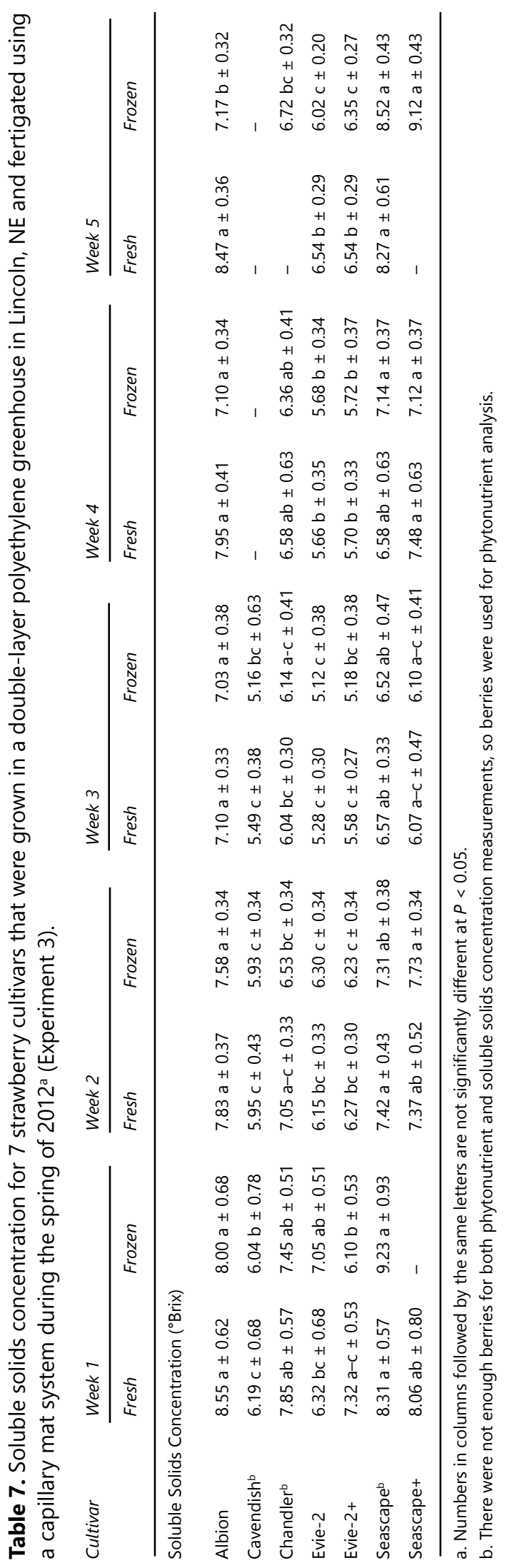




\section{Discussion}

The results of these experiments revealed three important findings. The first is that both June-bearing and day neutral cultivars can be brought to flower and fruit in the winter under natural light conditions in a double polyethylene greenhouse in the Great Plains. This is probably due in part to the naturally high incidental light as well as additional reflection provided by the white plastic on the bench tops. On a sunny day, PAR readings were recorded to peak between 600 and $1175 \mu$ moles $\mathrm{m}^{-2}$ $\mathrm{s}^{-1}$ (Meyer et al., 2010; Meyer et al., 2012). Further, not only did both response types of strawberries flower and fruit, but certain cultivars produced substantial yields over the 8-month growing periods. In comparing our results to others, on a per plant and total yield basis, our results were similar to or better than either strawberries grown using supplemental LED lights in plastic greenhouse production research (Korea; Choi et al., 2015) or those plants grown in either substrate or soil mix in a Brazilian single layer polyethylene greenhouse (Cecatto et al., 2013). Choi et al., 2015 found that plants that received certain LED wavelengths, in addition to natural light produced $5-15 \mathrm{~g}$ per plant over 3 weeks in December and 50-150 g per month each month over 4 months. During this study there was also a significant increase in berry phenolic compounds due to red light. Cettato et al., 2013 found that over a four-month period, monthly yields from 7 different varieties including "Portola" ranged from 0 to $2000 \mathrm{~g}$. In our work, the productivity of our cultivars may be due, not only to adequate quality and quantity of light, but to the use of dormant crowns, consistent temperature (under bench heating), correct medium composition, consistent water/nutrient supply via capillary mat and use of integrated pest management. All of these factors have been shown to affect growth and productivity as well as the concentrations of sugars and phytonutrients in field grown strawberries (Blando et al., 2012; Fan et al., 2012; Wang and Millner, 2009; Wang and Zheng, 2001; Wang et al., 2002).

However, our greenhouse production was not as consistent as desired. During the fall-winter, plants of "Albion", "Chandler", "Evie-2", Evie$2+$ ", "Seascape" and "Seascape +", yielded less than $28.4 \mathrm{~g}$ per plant per week. When day length substantially increased (late February), production increased to $56.7-411.3 \mathrm{~g}$ per plant per week. As fall/winter brings the highest prices for berries, the addition of supplemental lighting to increase day length should be explored. However, the initial purchase/ installation cost associated with LED or other supplemental lighting may not make this economically feasible. 
The second finding highlights our search for the best winter greenhouse cultivar. Unfortunately, no one cultivar produced berries with the desired combination of high phytonutrient and high sugar concentrations as well as high yield when grown under winter conditions. Over all 3 years, the phenol and flavonoid concentration as well as the ant oxidant capacity varied, but appeared to be more related to cultivar (e.g. low levels in "Portola" and "AC Wendy" versus high levels in "Darselect" and "Seascape") than to cultural factors such as the use of white plastic, consistent temperature via bottom heat and fertigation using the capillary mat system. Additionally, while this research demonstrated that berries of most cultivars had equal to or higher levels of sugars when compared to berries from the grocery store, the levels increased by only up to $16 \mathrm{mg} / \mathrm{g}$ of total sugars with glucose predominating. These values are lower than those reported by other scientists (e.g. "Camarosa" strawberries grown in plastic tunnels in Spain $-41 \mathrm{mg} / \mathrm{g}$ total sugars with proportionally more fructose (50\%) as compared to glucose (45\%) Akhatou and Fernandez-Recamales, 2014). This of course could be due any number of cultural/environmental factors, however, random tasting of berries by volunteers during our third experiment indicated that all cultivars tasted sweet and were pleasant to eat.

Additionally, our research did not explore different types or optimal concentrations of macro and micronutrients to determine if that factor could lead to higher sugar and/or phytonutrients under winter conditions. Paydas Yasa et al., 1996, working with different chemical fertilizers found that nutrients did not appear to alter fruit number or mass for greenhouse grown strawberries. However, this research did not explore varying the individual mineral element concentrations applied to these plants. Thus, experiments to determine optimal combinations of macro and micronutrients for use with capillary mat winter greenhouse systems could lead to higher sugar concentration and phytonutrient content without sacrificing yield.

Finally, this intensive production system also brought pest problems. Two cultivars, "Sweet Charlie" and "Albion" were particularly susceptible to two-spotted spider mites. Both cultivars exhibited a tight crown and denser growth habit than the others, which probably facilitated the infestation. Sugar concentration of the berries did not appear to be related to mite susceptibility as "Albion" plants had some of the sweetest berries while "Sweet Charlie" plants did not. As "Albion" plants had the desired December peak in experiment 2 and were excellent berry producers, it is recommended that if this cultivar is grown, an aggressive IPM plan be prepared and implemented (Price et al., 2002). 


\section{Conclusions}

Despite winter conditions, there is enough natural light coming into a double polyethylene greenhouse during the winter in the Great Plains to successfully grow strawberries. In all 3 experiments, use of a capillary mat for fertigation to save water and time, heat under the benches and a white reflective plastic on top of the mat resulted in successful flowering and fruiting of 13 cultivars. However, issues of labor for harvesting, cost of transportation to market and startup costs were not explored. Thus, technology transfer research focused on cost accounting to determine if winter strawberry production is profitable would be the next step.

Acknowledgments - The authors which to extend special thanks to Drs. Fumiomi Takeda and Barclay Poling for donation of plant material; Nate Nourse, Nourse Farms for dormant crowns and cultural advice and Dr. Walt Stroup for review of this manuscript. This research was supported in part by the Nebraska Department of Agriculture Horticulture Specialty Block Grants Program, USDA Multistate NE1035 and the Agricultural Research Division of the Institute of Agriculture and Natural Resources, University of Nebraska-Lincoln. Mention of specific trade names is for reference only and not to imply exclusion of others that may be suitable.

\section{References}

Adams, S.A., Paparozzi, E.T., 2014. Constructing a Block and Fence Growing Bench for Use with a Capillary Mat Irrigation System for Greenhouse Plant Production. EC 303. University of Nebraska-Lincoln Extension.

Adom, K.K., Liu, R.H., 2002. Antioxidant activity of grains. J. Agric. Food Chem. 50, 6182-6187.

Akhatou, I., Fernandez-Recamales, A., 2014. Nutritional and nutraceutical quality of strawberries in relation to harvest time and crop conditions. J. Agric. Food Chem. 62, 5749-5760.

Ballington, J., Polling, B., Olive, K., 2008. Day-neutral strawberry production for season extension in the midsouth. HortSci 43, 1982-1986.

Blando, F., Spirito, R., Gerardi, C., Durante, M., Nicoletti, I., 2012. Nutraceutical properties in organic strawberries from South Italy. Acta Hortic. 926, 683-690.

Boriss, H., Brunke, H., Kreith, M., 2010. Commodity Strawberry Profile. Agricultural Marketing Resource Center. lowa State University, Ames. lowa. http://www. agmrc.org/commodities_products/fruits/strawberries/commodity-strawberryprofile/ (2012; Accessed June 17, 2014, update by Morgan, K. L.).

Cao, G., Alessio, H.M., Cutler, R.G., 1993. Oxygen-radical absorbance capacity assay for antioxidants. Free Rad. Biol. Med. 14, 303-311. 
Cecatto, A.P., Calvete, E.O., Nienow, A.A., Castoldi da Costa, R., Mendonça, H.F.C., Pazzinato, A.C., 2013. Culture systems in the production and quality of strawberry cultivars. Acta Sci. 35, 471-478.

Choi, H.G., Moon, B.Y., Kang, N.J., 2015. Effects of LED light on the production of strawberry during cultivation in a plastic greenhouse and in a growth chamber. Sci. Hortic. 189, 22-31.

Fan, L., Dube, C., Fang, C., Roussel, D., Charles, M.T., Desjardins, Y., Khanizadeh, S., 2012. Effect of production systems on phenolic composition and oxygen radical absorbance capacity of "Orleans" strawberry. Food Sci. Technol. 45, 241-245.

Gbur, E.E., Stroup, W.W., McCarter, K.S., Durham, S., Young, L.J., Christman, M., West, M., Kramer, M., 2012. Analysis of Generalized Linear Mixed Models in the Agricultural and Natural Resources Sciences. Agronomy Society of America, Madison, Wl.

Keutgen, A.J., Pawelzik, E., 2007. Modifications of taste-relevant compounds in strawberry fruit under $\mathrm{NaCl}$ salinity. Food Chem. 105, 1487-1494.

Lambe, D.P., Adams, S.A., Paparozzi, E.T., 2012. Estimating Construction Costs for a Low-Cost Quonset-style Greenhouse. EC104. University of Nebraska-Lincoln Extension.

Lieten, F., 1993. Influence of peat composition on the productivity of "Elsanta" strawberry plants grown on substrate. Acta Hortic. 348, 361-365.

Littell, R.C., Milliken, G.A., Stroup, W.W., Wolfinger, R.D., Schabenberger, O., 2006. SAS for Mixed Models, Second edition. SAS Institute, Cary, NC.

Mattas, K., Tzouamani, I., Paroussi, G., Bentes, M., 1997. Assessing the economic efficiency of a soilless culture system for off-season strawberry production. HortSci 32, 1126-1129.

Meyer, G.E., Paparozzi, E.T., Walter-Shea, E., Adams, S.A., 2010. Use of Reflective PAR Mulches to Enhance Winter-time Greenhouse Strawberry Production. ASABE Paper Number 1009783. In: St. Joseph, MI. Amer. Soc. Agr. Biol. Eng..

Meyer, G.E., Paparozzi, E.T., Walter-Shea, E., Blankenship, E.E., Adams, S.A., 2012. An investigation of reflective mulches for use over capillary mat systems for winter-time greenhouse strawberry production. Appl. Eng. Agric. 28 (2), 271-279.

Paparozzi, E.T., Meyer, G.E., 2012. The return of capillary mats. Greenhouse Grower $30,78-84$.

Paparozzi, E.T., 2013. The challenges of growing strawberries in the greenhouse. HortTechnol 23 (6), 800-802.

Paydas Yasa, E., Kaftanoglu, O., Ozdemir, G., Kaska, N., Caglar, H., 1996. Effects of different chemical fertilizers on the yield and quality of some strawberry cultivars grown in a glasshouse. Acta Hortic. 422, 268-272.

Price, J.F., Legard, D.E., Chandler, C.K., McCord, E., 2002. In: Hokanson, S.C., Jamieson, A.R. (Eds.), Changes in Florida Strawberry Production in Response to Two Spotted Spider Mite Resistance to Agri-Mek Abamectin in Strawberry Research to 2001. ASHS Press, Alexandria, VA.

Rowley, D., Black, B.L., Drost, D., Feuz, D., 2011. Late season strawberry production using day-neutral cultivars in high-elevation high tunnels. HortSci 46, 1480-1485. 
Royal Horticultural Society, 1995. RHS Colour Chart. The Royal Horticultural Society, London.

Singleton, V.L., Rossi, J.A., 1965. Colorimetry of total phenolics in grapes and wine with phosphomolybdic-phosphotungistic acid reagents. Am. J. Enol. Viticult. 16 (30), 144-158.

Takeda, F., Hokanson, S.C. 2002. Effects of transplant conditioning on "Chandler" strawberry performance in a winter greenhouse production system. In: Proceedings of the 5th North American Strawberry Conference. Strawberry Research to 2001. Hokanson, S.C., A.R. Jamieson (eds.). ASHS Press, Alexandria, VA. p. 132-135.

Wang, S.Y., Millner, P., 2009. Effect of different cultural systems on antioxidant capacity, phenolic content, and fruit quality of strawberries (Fragaria $\times$ aranassa Duch.). J. Agric. Food Chem. 57, 9651-9657.

Wang, S.Y., Zheng, W., 2001. Effect of plant growth temperature on antioxidant capacity in strawberry. J. Agric. Food Chem. 49, 4977-4982.

Wang, S.Y., Zheng, W., Galletta, G., 2002. Cultural system affects fruit quality and antioxidant capacity in strawberries. J. Agric. Food Chem. 50, 6534-6542. 